\title{
NBSIR 75.699
}

\section{The Calibration of Photographic Edges at NBS}

Richard E. Swing

Institute for Basic Standards

National Bureau of Standards

Washington, D. C. 20234

April 22, 1975

Interim Report

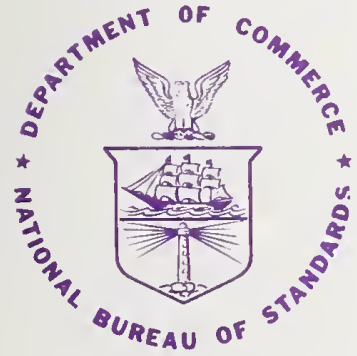

U.S. DEPARTMENT OF COMMERCE

NATIONAL BUREAU OF STANDARDS 

NBSIR 75-699

\section{THE CALIBRATION OF PHOTOGRAPHIC}

\section{EDGES AT NBS}

Richard E. Swing

Institute for Basic Standards National Bureau of Standards

Washington, D. C. 20234

April 22, 1975

Interim Report

U.S. DEPARTMENT OF COMMERCE, Pogers C.B. Morton, Secrotan

NATIONAL OUREAU OF STANDAROS, Riched $w$. Roberts. OHector 

This document has been prepared as part of the program to upgrade and improve the density-measurement capability at NBS through research in the Optics and Micrometrology Section of the Optical Physics Division. It is the second of several that will be released in this subject-area, and will occaslonally undergo revision and expansion as the need arises. At the end of the program, a complete NBS report on Densitometry and related matters will be prepared and published. 



\section{INTRODUCTION}

NBS has produced photographic edges for optical and photographic emulsion testing for more than ten years, but has lacked a quantitative analyt1cal procedure to certify their quality. The technlque used to make these edges employs $x$-ray exposure of high resolution plates (with a thin tantalum strip for the edgediscontinuity), and their subsequent chemical processing is aimed at preventing adfacency effects. Because of the avallable $x$-ray equipment, exposure quality and unfformity have not always been consistent, and a need for quant1tative evaluation of the edge has always existed.

Past evaluative procedures traced the edge on the NBS mlcrodensitometer (a Kodak Model III, modifled) and inspected the obvious characteristics of the chart record such as steepness of slope, symmetry, exposure or processing varlations manifested by the lack of smoothness in the trace and the varlation in density on the toe and shoulder (to detect possible adjacency effects), always in a qualitative manner. The present note is concerned with computer analysis of the traces to quantify the statements made about the edges and their quallty.

\section{THE ANALYSIS OF EDGES}

The major parameter used to characterize the edge is called acutance. This is a property that relates to subjective (visual) judgements of "sharpness," and 1s discussed in more detail in Ref. 1. It is a calculation of the mean-square slope of an edge, between two points along 1t, corrected (or adjusted) for the density difference between these points. This note documents a computer program called ACUMTF that calculates this quant1ty.

A further consideration of this note is the use of edges to test or evaluate an optical instrment through a procedure known as edgegradient analys1s. When the edge is placed in a microdensitometer and scanned, the resulting chart record can be analyzed to determine the optical transfer function of the microdensitometer. There are other varlations to edge-analysis, but this is the only one considered in this note. To carry out these calculations, a second program is needed. It is called EMIFER and this note also documents that program.

* Certain cormercial instruments and equipment are 1dentified in this report in order to specify the experimental procedure adequately. In no case does such identification imply recommendation or endorsement by NBS, nor does 1t imply that the equipment identifled is necessarlly the best avallable for the purpose. Further, the equipment may not be Identical to those models in current production that bear nominally similar designations of model type. 
Finally, because a plot of the modulation transfer function (MIF) is often useful for diagnostic and display purposes, a program that plots the MIF produced by EMIFEER has been prepared. It is called MIFPLT, and this note documents that program as well.

All three programs are written in BASIC, a language often avallable on the time-sharing computers of the kind used at NBS by the Optics and Micrometrology Section. Such systems are adequate for the task, are easily used by the Inexperlenced, the costs are low and the turn-around-time is short. For the accuracy commensurate with the analyses described in this note, use of a more sophisticated computer with a higher-level programing language would not be cost-effective and would probably provide a computational "overkill." Since these programs might also be useful to those outside NBS, 1t was felt that the BASIC language would offer the least problem in adaptation to other computers. These three program are used at NBS, exactly as written and listed in this note, to callbrate and examine photographic edges made there.

The various plots and flgures of this note all derive from the same density calibration and edge-trace information located in the data section of ACUMTF.

ACUMTF

The program ACUMTF calculates acutance from a microdensitometer trace of an edge. Acutance is defined analytically by

$n$

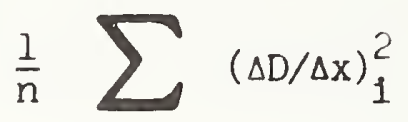

Acutance $=\frac{1=1}{D_{b}-D_{a}}$.

In this equation, $D_{b}-D_{a}$ is the density range over which the actual calculations are made. The end-polnts of the calculation are critical; if too much of the edge trace is included, the value of acutance will be too low, while the opposite it true if too little is included. It was found (Ref. 1) that the end points should be located on that portion of the trace where the slope $(\Delta D / \Delta x)=0.005$, with $x$ measured in micrometres. The accuracy of the calculations is improved when $n$, the number of $(\Delta D / \Delta x)$ 's, is large.

Originally, acutance was devised to measure an attribute of photographic images that would correlate well with subjective impressions of image "sharpness." Thus, the 1mage of an edge of the photographic materlal was analyzed and the property, acutance, ascribed to the materlal itself. The higher the value of acutance, the higher the corresponding quallty. However, if the edge itself is traced, an 
analogous acutance can be calculated for a given set of microdensitometer parameters. This acutance applies only to the given set of parameters, and constitutes a callbration of sorts when those conditions can be duplicated on another instrument. When edges of extremely high acutance (values of 100,000 and larger) are used to test an optical instrument, no significant correction need be applied for the inherent imperfections of the edge, unless the response of the instrument itself approaches the quality of the edge. The program ACUMTF is intended for use in calibrating the edges made at NBS. When reported, values of acutance are always accompanied by details of the optics of the microdensitometer making the trace. Because of the problems of alignment of the scanning slit with respect to the edge, acutance values are always the average of at least three separate determinations. A listing of ACUMIF is shown in Appendix A.

Data Input to ACUMTF

The bas1c data for ACUMTF are:

1) A density calibration, in the form of diffuse density versus chart reading, and

2) An edge-trace, in the form of chart reading versus distance across the edge, taken from the chart recording produced by the (NBS) Kodak Model III microdensitometer.

Standard Instrument callbration procedures are employed. A step tablet of the same material as that of the edge (and usually processed with 1t) whose density values are determined on a macrodensitometer measuring diffuse (visual) density is scanned in the microdensitometer. The values of chart reading versus diffuse (visual) density are then input on lines 900 through 915 . Line 900 always contains the number of palrs of points, while the succeeding lines contain the point-pairs:

a) List chart reading and density, in that order, in pairs, in increasing order. It is important that both density and chart reading be listed in increasing order; the program will not provide a correct calibration table otherwise. See lines 910 through 914 of the ACUMTF listing for a specific example.

b) Do not interpolate visualiy on the chart recording to other than one-half a scale division; 1.e., a value of 15.3 , say, cannot be entered: 1t must be either 15.0 or 15.5 . This is consistent with the inherent accuracy of the acutance calculations and the density calibration of the program, and will carry over to analysis of the edge-trace record.

For the chart reading versus scanned distance, refer to Figure 1. The following procedure is employed in choosing points. 
1) Determine the end-points first; these are the points where the slope of the trace goes to zero. Scrutinfze the trace carefully; the decision is critical. The end points should be located exactly where the slope goes to zero, within the restralnts of the one-half scale division previously c1ted.

2) Select an arbitrary origin, away, from the curve on the lower-density portion of the trace. Measure everything from this point. Since the chart paper usually has divisions of $1 / 10$-1nch, it is conventent to use the paper 1tself for measurement. The listing of the points, in Figure 1 1llustrates this.

3) Choose as many points along the curve as is consistent with Its delineation, listing them (both chart reading and scanned distance) to the nearest one-half scale division. Figure 1 1llustrates the polnts chosen and lists all those used. Use as many as needed to characterize the trace accurately: but do not use less than 18 not more than 38*. Do not take points so close together that, because of rounding to the nearest half-scale division, there are consecutive pairs having the same value of Chart Reading (e.g., ...28.5,0.20,28.5,0.25,...). Th1s will lead to serious computational problems in the subsequent acutance determination.

4) So that the interpolating routine in the program has sufficlent information at the ends of the scale, include points at elther end one chart division away from the end point, repeating the value of chart reading. These are placed in lines 917 and 925 of the ACUMTF program listing for emphasis, and must be included in the total number of pointpairs on line 916. Table I shows the listing that would finally accompany the data taken from Flgure 1.

5) Determine the trace constant for the microdensitometer; this constant converts inches on the chart to micrometres on the sample, and is a function of scan speed and chart speed. The constant can be found in the microdensitometer operating manual for the varlous speeds used by the instrument. For the trace shown in the Flgure 1, that constant has a value of 3.048 .

6) Enter edge-data in ACUMTF as follows:

a) Line 916 contains the number of pairs of points (chart reading, scan distance) and the trace constant; Thus . . . .916 Data 21,3.048 . . for the data of Table I.

b) Line 917 and subsequent contains the points (chart reading, distance), in that order, in pairs, in ascending (Increasing) order.

*Th1s is limited by the program array s1ze, lines 015 and 016 of the listing. 


\section{TABLE I}

Complete L1st of Point-Pa1rs

for Edge-Trace in Figure 1

\begin{tabular}{l|l}
\hline $\begin{array}{l}\text { Chart } \\
\text { Reading }\end{array}$ & $\begin{array}{l}\text { Distance } \\
\text { (Inches) }\end{array}$ \\
\hline 15.0 & 0.20 \\
15.0 & 0.30 \\
15.5 & 0.65 \\
16.0 & 0.80 \\
17.0 & 0.95 \\
19.0 & 1.10 \\
20.5 & 1.20 \\
22.5 & 1.30 \\
25.0 & 1.40 \\
28.0 & 1.50 \\
31.5 & 1.60 \\
35.5 & 1.70 \\
40.0 & 1.80 \\
45.5 & 1.90 \\
50.5 & 2.00 \\
53.0 & 2.10 \\
56.5 & 2.25 \\
57.0 & 2.30 \\
58.0 & 2.45 \\
58.5 & 2.70 \\
58.5 & 2.80 \\
&
\end{tabular}


Consult lines 916 through 925 of the ACUMTF listing for a specific example.

Program Synopsis

Once the data have been patched-1n, the program carrles out the following operations in sequence: it first reads the data into the program and prints 1t. This allows a visual check of the callbration information. The program then calculates a calibration look-up table, but does not print 1t. A spline-fitting technique is used to accomplish this [2].

The edge-trace data are now read into the program, converting the chart readings to density, through the look-up table previously prepared, and the scanned distance from inches to micrometres. The density values are converted to transmittance and the data are inverted (in order of increasing distance and transmittance) in antic1pation of eventual use in determining transfer function. The basic edge-trace Information 1s then printed out, together with the adjusted edge-transmittance versus distance pairings.

The acutance calculation follows this. First the program finds the end points by searching for the points where $(\Delta D / \Delta x)=0.005$. Since the data are digitized, there may not be a point that has that exact value in the listing. Therefore, the program chooses the next h1gher value at the low-density end of the trace and the next lower value at the high-density end of the trace. To provide the user with the value of the point that preceded the one used in the calculation, It is printed to the right of the end-points in the listing of Flgure 2. This manner of choice is entirely arbitrary, and may lead to a value of acutance that is slightly higher than the "true" value. Once the end-points have been chosen, the values of the slope are squared and summed. Acutance is then calculated. The values of $\mathrm{D}_{\mathrm{b}}$ and $\mathrm{D}_{\mathrm{a}}$ are printed out, respectively as D-MAX and D-MIN, with the values of the slope at the end-points following (and 1dentified). The value of acutance, rounded to three significant floures, is then printed. For a complete print-out of a typical ACUMTF mun, see Figure 2.

At this point, the user is given a cholce. If he 1s interested in continuing the calculations to transfer function, it is necessary to transfer the pertinent edge-data (in terms of transmittance and distance) to another program. ACUMTF prints the instructions for this step, and asks the user to respond with a "l" 1f transfer function calculation are required, and a "2" if not. Both printouts and responses are shown in Append1x A, following the program listing. It should be noted that the two outermost data noints, one on either side of the edge-data corresponding to the l1st in Table I, are not put into the data f1le. Subsequently, the program notifles the user of the data transfer and instructs him to mun the program EMIFER. No other input is required for that program to be executed. However, it may not be executed without first running ACUMIF. 
BASIC CAL IBKAIISV UATA

$\begin{array}{rr}\text { CHAKT } & \text { UIFFUSE } \\ \text { KFAUING } & \text { UEINSITY } \\ .0 & .00 \\ 1.0 & .04 \\ 10.5 & .35 \\ 17.0 & .60 \\ 25.5 & .88 \\ 41.0 & 1.42 \\ 54.5 & 1.87 \\ 65.0 & 2.26 \\ 72.5 & 2.55 \\ 79.0 & 2.78 \\ 91.5 & 3.20\end{array}$

BASIC EUGE-TKACE UATA

$\begin{array}{clc}\text { CHAKT } & \text { DIFHUE } & \text { SAMHLE } \\ \text { READING } & \text { DENSITY } & \text { DISTANCE }\end{array}$

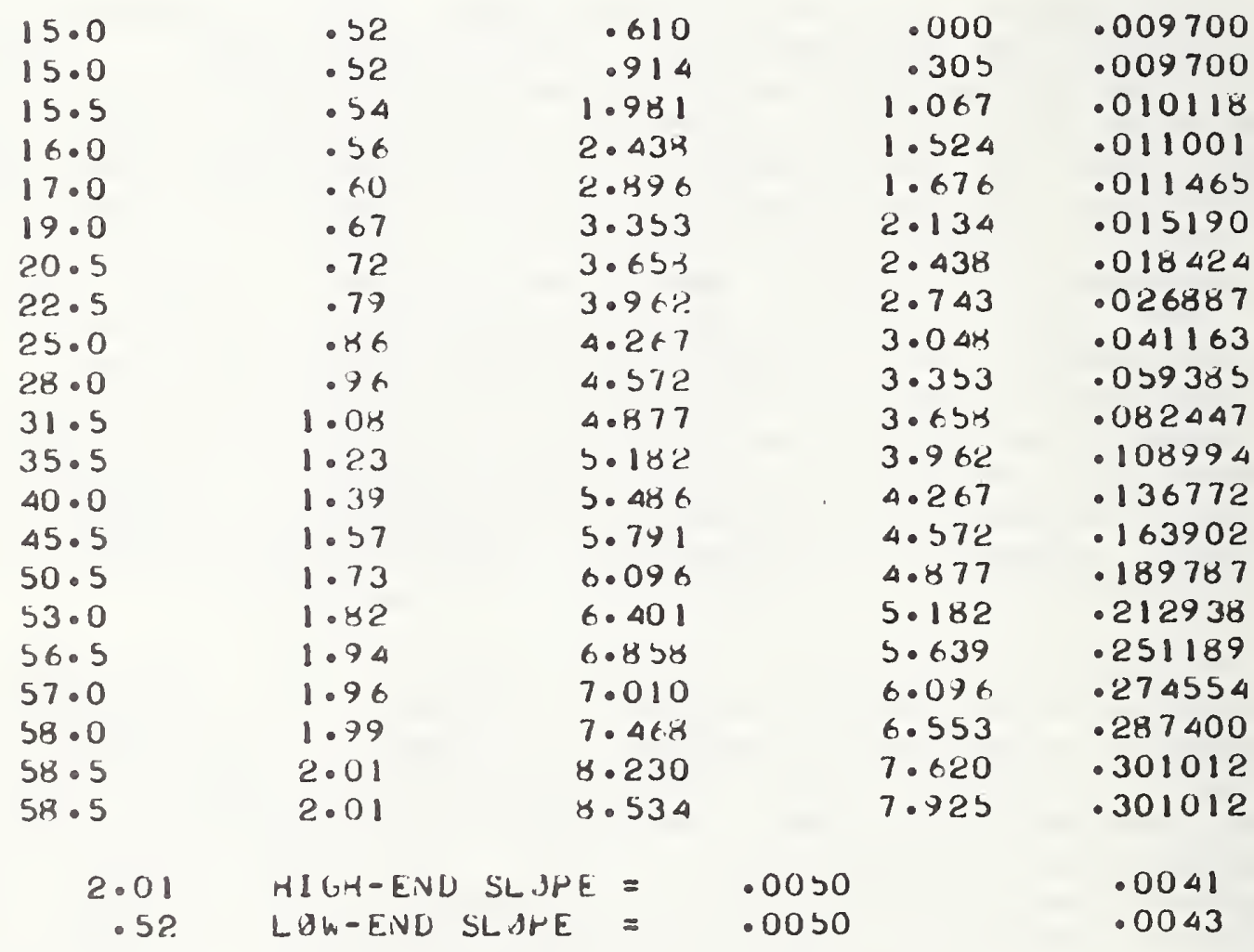

$D-M A X=$

- 52 .

LOW-END SLOHE =

.0050

ADJUSTED EDGE

TKANSMI T TANCE

$D-M I N=$

ACUTANCE $=\$ 1600$

Figure 2: Typical printout of ACUMTF. 
Error Analysis:

The possible error in the calculation of acutance is related directly to the specification that data be read from the chart to the nearest 1/2-scale division. In the ordinate (density), the microdensitometer is adjusted to cover from 0 to 3.0 over 80 full scale divisions. This glves a factor of 0.02 density units/half-scale division. We w1Il assume that the careful operator w1ll make no more than a one-quarter scale division error in reading, so that the maxtmum error in density should be no more than 0.01 .

In the abscissa (scan distance), we w1ll use the slowest microdensitometer speed. This provides 3.048 micrometres on the sample per inch on the chart. The chart is marked in 1/10-inch scale divisions. With this, on the sample, we w1ll have 0.15 micrometres/half-scale division. Assuming the same quarter-scale division reading emror that we did for density, the maximm error in scan distance (on the sample) is estimated to be no more than 0.075 micrometres.

The program spline-fits and expands the callbration and edge-data, the latter to approximately 350 points. The basis of this fit is a 3 rd-degree polynomial and the transitions are smooth (the derlvatives must match at the ends of adjoining fitted segments). We w1II therefore assume there is no significant contribution to the error in acutance from the program except for that associated with the cholce of end-points previously discussed. Because density and chart reading can only be specified to three signiflcant figures, information derlved from the calculations of the programs considered in this note w11l be printed to no greater than three significant rigures.

Referring to the input data (taken rram the edge-trace record and the density calibration data), we can show that the estimated relative emor in acutance is given approximately by

$$
E(\text { rel })=\frac{4}{N}\left[\frac{\beta}{\overline{\Delta D}}+\frac{\xi}{\overline{\Delta x}}\right]+\frac{2 \beta}{D_{b}-D_{a}} \text {, }
$$

where

$$
\begin{aligned}
N & =\text { mumber of data points; } \\
B & =\text { measurement error in density }(0.01) ; \\
\xi & =\text { measurement error in scan distance }(0.075 \mathrm{um}) ; \\
\overline{\Delta D} & =\text { average tabular density difference; } \\
\overline{\Delta x} & =\text { average tabular scan distance difference }(\mu \mathrm{m}) ;
\end{aligned}
$$




$$
\begin{aligned}
& D_{b}=\text { maximum dens1ty for acutance calculation; } \\
& D_{a}=\text { minlmum dens1ty for acutance calculation. }
\end{aligned}
$$

For the data shown in Figrure 2,

$$
\begin{aligned}
N & =19 ; \\
\overline{\Delta D} & =0.08 ; \\
\overline{\Delta x} & =0.41 ; \\
D_{b} & =2.01 ; \\
D_{a} & =0.52 .
\end{aligned}
$$

When these are inserted into the above equation, we obtain

$$
E(\text { rel })=8 \% \text {, }
$$

and the value of acutance is properly glven as

$$
\text { Acutance }=51,600 \pm 4100 \text {. }
$$

These estimates of accuracy are consistent with this method of data analysis in the time-sharing computer. The calculated error can be reduced somewhat by using more data points, but to make a significant improvement in accuracy, $1 t$ w1ll be necessary to take data from the microdensitometer on magnetic tape and subsequently process the information in a more comprehensive program. It should also be noted that the expression for relative error is only approximate: the error changes inversely as a function of acutance. As calculated above, it represents maximum relative error. Since the data for subsequent programs documented in this note depend on this calculation, the same accuracy can be ascribed to their results. As a general gulde, based on these considerations and expertence with the procedure at NBS, the relative error in acutance (for the technlques outlined here) can be taken to be not less than $5 \%$ nor greater than $10 \%$.

\section{EMIFER}

The program EMIFER calculates the optical transfer function of the microdensitometer from analysis of the eds?-trace record, on the assumption that the edge quality is sufficlently high to warrant no 
corresponding correction to the trace-data". When the edge is moved through the opt1cal axis of the instrument (assuming a slit has been adjusted parallel to the edge and that the adjustment of all optics and related mechanlcal fixtures has been optimized), the 1Iluminance falling on the photodetector wlll be given by

$$
I(x)=\int E\left(x-x^{\prime}\right) r^{\prime}\left(x^{\prime}\right) d x^{\prime},
$$

where $E\left(x^{\prime}\right)$ is the edge-object radiance and $f\left(x^{\prime}\right)$ is the impulse response of the optical system. In pract1ce, the photometer output is converted to chart reading. In turn, this is converted to density and then transmittance (the equivalent of 1lluminance in this context) through the preceding program, ACUMTF. To simplify the presentation, we will retain the identity of the edge through use of $E\left(x^{\prime}\right)$ and bypass the chart reading-density-transmittance procedure.

Because the edge is the signum function, 1.e.,

$$
\begin{aligned}
E\left(x^{\prime}\right) & =\operatorname{sgn}\left(x^{\prime}\right), & & \\
& =1 ; & & \left(0<x^{\prime}\right) \\
& =-1 ; & & \left(0>x^{\prime}\right)
\end{aligned}
$$

we can rewrite Eq. (2) as

$$
I(x)=\int_{-\infty}^{x} f\left(x^{\prime}\right) d x^{\prime} .
$$

\footnotetext{
When the edge is of lesser quality, the result is an admixture of the MIF and the edge characteristics, and what is determined is its spectrum. On the other hand, for a k,iven edge-making process, a measure of the consistency of the process and 1ts analysis through ACUMIF and EMITER is the accuracy with which this "MIF" is reproduced from edge to edge for the same set of optical parameters. It is also a useful means for checking instrument adjustment; on the same edge, the "MTF" should be reproduced. If not, the instrument will have been incorrectly adjusted.
} 
When we differentiate both sides of this equation, we obtain

$$
f(x)=\frac{d}{d x}(I(x))
$$

and we have thus derlved the impulse response of the opt1cal system. Since the Fourler Transform of the impulse response 1 s the transfer function, we w1ll have

$$
\begin{aligned}
f^{\prime}(\sigma) & =\int f(x) \exp (-2 \pi 10 x) d x \\
& =\int\left[\frac{d}{d x} I(x)\right] \exp (-2 \pi 10 x) d x,
\end{aligned}
$$

and the Fourler Transform of the differentiated edge-image distribution is the optical transfer function.

This 1s clearly an ideallzation. For relatively nolse-free edges such as those produced at NBS, no allowances need be made for the nolse contributed by the grain in the emulsion of the photographic process, 1.e., no smoothing of the edge-data is required. On the other hand, when edge-gradient analys1s is used to obtain MIF from nolsy data, large errors can result unless the data are smoothed (f1ltered): there can be little confidence in the results. Because of this, edge-gradient analysis is (generally) not a particularly accurate technique. Even allowing for a certain amount of smoothing, the procedure surfers from the fact that because the spectrum of an edge falls off as the reclprocal of spatial frequency, the data in those regtions of particular interest (the high-frequency portion of the curve) are produced with a low signal-to-nolse ratio. There are st1Il other considerations that mitigate agalnst the accuracy and precision of this method. However, the technique is easily implemented and results can be interpreted with little ambigulty. In many cases, it is the only avallable technique. But the user should not assign undue confldence to the results; 10\% RMS error in transfer function is often about the best that can be achieved; with experlence and increased technical skdli in carrylng out the measurements, this can sometimes be reduced to 5\%. Nothing better than this is warranted and should not be expected.

The program EMIFER embodies the operations described by Eqs. (2) through (6). Because the differentlation of the edge produces the impulse response with values of zero on elther side, a direct Fourler transformation can be carried out. For reasons of accuracy, the numerical integration was implemented through Weddle's Rule [3]. 
Weddle's Rule requires that there be $N=6 M+1$ data points in the calculation, where $M$ is an Integer chosen large enough for accuracy and small enough to keep the avallable arrays within bounds. In keepling with the limitations of the size of BASIC programs, a value of 33 was chosen for M, whlch thereby gave 199 for $N$, and an array of 200 values is used for the edge analyzed in the program. The given edge information is expanded by interpolation through a spline-fitting technique [2] and occuples the full 200-element array. Subsequently, because the spline-flt coefriclents are avaliable, the derivative is calculated on the basis of the algorithm.

Data Input to EMTFER:

The input for EMIFER comes from ACUMIF. It is left in a file within the computer, from which EMTFER draws. It. EMTFER cannot be executed unless ACUMTF is first mun. A complete listing of EMIFER is shown in Append1x B.

Program Synopsis:

Once the data file has been provided, the program carrles out the following operations. Before processing the data, the program asks the user if a plot of the MTF is required. If the response is affirmative, a data file is set up imediately and fllled during the ensuing calculations. This is a necessary because EMIFER uses nearly all of the avallable space in the computer and another array camot be set up.

The program then reads the data and prints it (a patch-routine is subsequently provlded that permits skippling the printing: see Appendix $B$, following the listing). This allows a check on the input data (1t should agree with the edge-1ist printed by ACUMIF). The edge data are next expanded Into the 200-element array and the derivative calculated. Following this, the array is set up for integration by Weddle's Rule and the array summed: this is the area under the impulse response and it is used for normallzing the transfer function.

The Fourler transform of the edge distribution is next calculated. The cosine and sine transforms are calculated separately so that the modulus and phase of the optical transfer function can be determined. As the calculation is made, the results are printed, frequency by frequency, and the data file is filled. The print-out is based on increments of $10 \mathrm{cycles} / \mathrm{mm}$. this value 18 arbitrary, and is contalned in line 185 of the listing;

$$
185 \mathrm{~F}=10 \text {. }
$$


It can be changed by patching-in the desired value prior to execution of the program.

The print-out (and calculation) is stopped arbitrarily at an MTF value of 0.04 . This threshold value can be changed if desired. The appropriate line in EMIFER reads:

$$
216 \text { IF }(S 3-0.04), 302,302,220 \text {. }
$$

If a higher or lower threshold is required, rewrite the line with the desired value subst1tuted for 0.04 .

When a plot is required (and has been indicated prlor to carrying out the calculations), a data flle wlll have been set up for the program MIFPLT and after the completion of the transfer function calculations the computer w1Il not1fy the user that MIFPLT should next be run. Typical print-out of these instructions and their responses are shown in Appendix B, following the program llsting.

The print-out of EMI'FER is in two parts. The first lists the edge information, following the question/answer about plotting. This is shown 1s Flgure 3. The second is the listing of the MIF, and is shown in Figure 4.

MIFPLT

The program MIFPLT plots the modulation transfer function (MIF) calculated by the program EMTFER through edge-gradient analysis. It Is specifically tailored for this single purpose, and assumes the 10 cycle/mm increment in spatial rrequency used by EMIFER in its calculations. MIFPLT derives Its input data only from EMTFER.

Program Synops1s:

The program reads the data from the flle set up by EMIFER. The fundamental plotting increment along the ordinate scale 1s 0.04 . The data are then tested against this increment, sorted accordingly, and

* The user is cautioned that the routine for flotting the MTF assumes this value of spatial frequency as an increment. MIFPLT must be modifled accordingly, if line 185 is changed and a plot is subsequently desired. 


\section{?BASIC EMTFER}

\section{RUN}

IF A PLOT OF THE MTF IS DESIRED, TYPE I AFTER ! OTHERWISE, TYPE 2 .

! 1

\begin{tabular}{|c|c|}
\hline $\begin{array}{l}\text { TRACE DISTANCE } \\
\text { (MICROMETERS) }\end{array}$ & TRANSMI T TANCE \\
\hline .000 & .009700 \\
\hline .762 & .010118 \\
\hline $1 \cdot 219$ & .011001 \\
\hline $1 \cdot 372$ & .011465 \\
\hline $1 \cdot 829$ & .015190 \\
\hline $2 \cdot 134$ & .018424 \\
\hline $2 \cdot 438$ & .026887 \\
\hline $2 \cdot 743$ & .041163 \\
\hline $3 \cdot 048$ & .059385 \\
\hline $3 \cdot 353$ & .082447 \\
\hline $3 \cdot 658$ & .108994 \\
\hline 3.962 & .136772 \\
\hline $4 \cdot 267$ & .163902 \\
\hline 4.572 & - 189787 \\
\hline $4 \cdot 877$ & .212938 \\
\hline $5 \cdot 334$ & .251189 \\
\hline $5 \cdot 791$ & .274554 \\
\hline $6 \cdot 248$ & - 287400 \\
\hline $7 \cdot 315$ & .301012 \\
\hline
\end{tabular}

Figure 3: Typical edge-information printout of EMTFER, showing the initial program instruction for subsequent plotting of MIF. 
TRANSFEK PUVCTIJN

FKEQ -

0
10
20
30
40
50
60
70
80
90
100
110
120
130
140
150
160
170
180
190
200
210
220
230
240
250
260
270
280
290
300
310

MIF

$$
1.000
$$$$
.997
$$$$
\text { . } 989
$$

.976

.957

.934

.906

.874

.839

.800

.759

.715

- 670

- 624

.577

. 531

. 485

- 439

. 396

. 353

. 313

.275

- 240

.206

.176

- 148

- 123

.101

.081

.063

. 049

.036
RHASE

$$
\begin{array}{r}
.000 \\
.264 \\
.527 \\
.791 \\
1.054 \\
1.318 \\
-1.560 \\
-1.297 \\
-1.034 \\
-.771
\end{array}
$$

-.509

$-.247$

. 015

.276

. 536

.796

1.054

1. 312

1. 568

$-1.320$

$-1.068$

$-.819$

-. 573

-.331

-.094

. 135

. 357

.566

.760

.929

1.062

1.135

Figure 4: Typical printout of EMTFER. 
rounded to the nearest 0.04 . The graph axes and points are then printed together, starting with the topmost ordinate value and working down to the $x$-axis. Increments on the $x$-axis are 10 cycles $/ \mathrm{mm}$.

The program is presently limited to positive values of MIF; only one curve can be plotted. Multiple-valued functions (such as those produced by a central obstruction in the aperture) will not plot correctly with the present sorting algorithm.

A typical print-out from this program is shown in Figure 5. 
MODULATIUN TKANSFEK PUNCTION

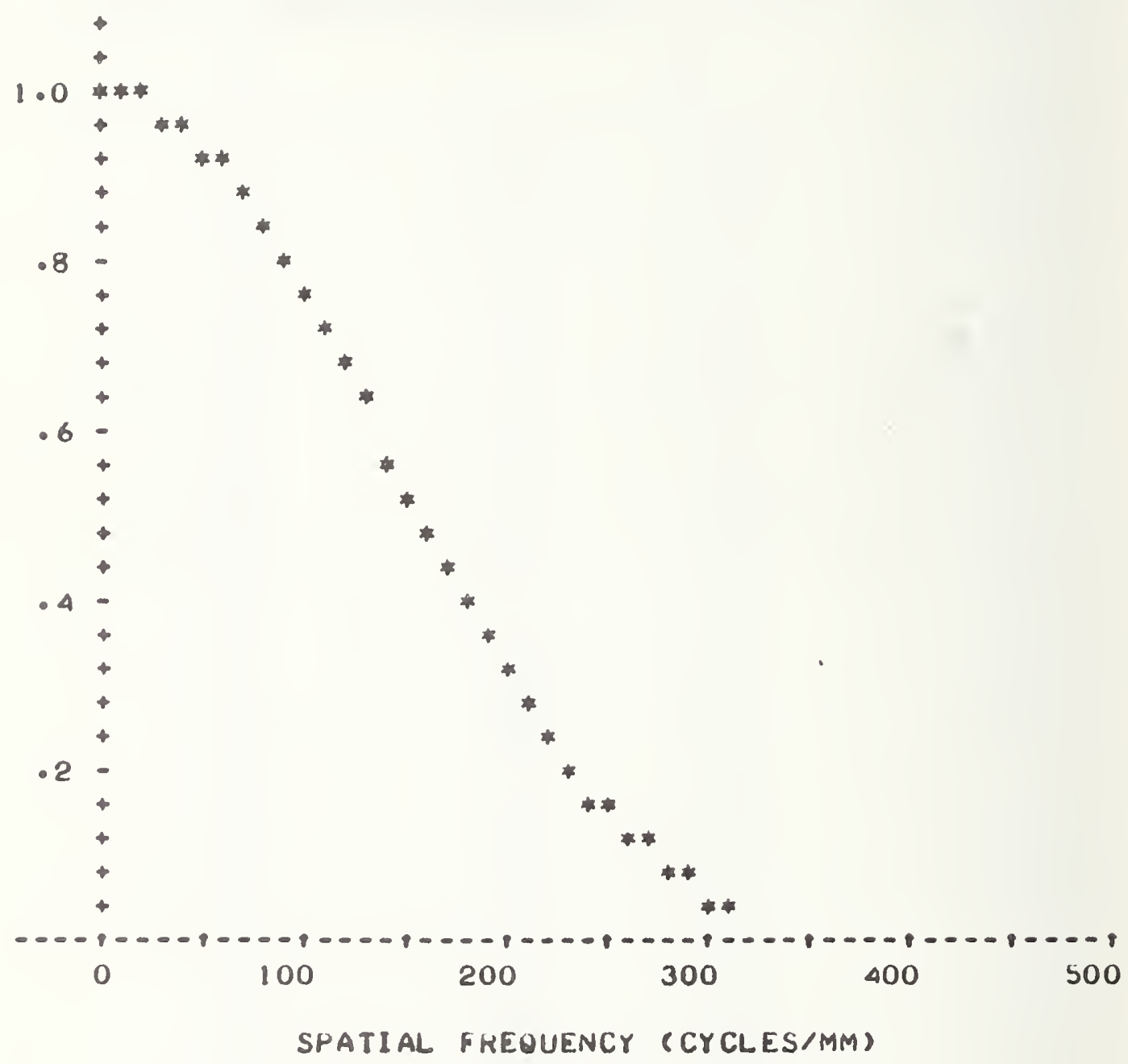

Figure 5: Typical printout of MTPPLT. 
REFERENCE:

[1] C.E.K. Mees and T.H. James, The Theory of the Photographlc Process, 3rd Ed. (New York, The MacMillan Company, 1966), p. 511.

[2] R. H. Pennington, Introductory Computer Methods and Numerical Analysis, 2nd Ed. (The MacMllian Company, Collier MacMilian Canada, Ltd, Toronto, Ontar1o, 1970), pp. 445-454.

[3] J. B. Scarborough, Numertcal Mathematical Analys1s, and Ed. (The Johns Hopkins Press, Baltimore, Md., 1950), pp. 133-137, 180. 
APPENDIX A

ACUMIF - A Program for Calculation of Acutance 
OO1 * KICHAKD E. SWING, 232.06, X21S3, RKAGKAM: ACUMTF

003 *

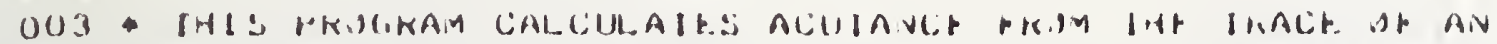

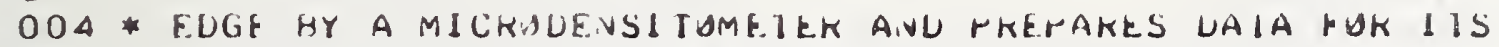

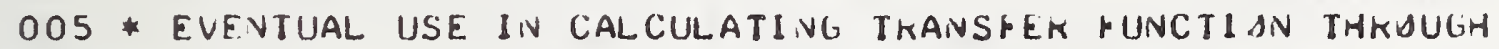

OOG * THE rROgRAM CALLED EMTrEK.

$007 *$

015 DIM $x(40), Y(40), U(40), H(40), E(40), C(4,40), A(40,4)$

016 DIM $B(40), Z(40), K(40), F(40), T(40), V(40)$

017 DIM G(350), H(350),L (350), K( 350$)$

$018 *$

$02001=1$

$021 F I X K J=1 T H 5$

022 PRINT

0 ? 3 NEXT J

024 READ $M$

025 GS TU 270

$026 F M I=1$ TS $M$

- I ivput densitr cal lbKalidiv luta.

027 READ X(I),Y (I)

028 PRINT, 029, X(I), Y (I)

029 F.MT X2.1,F8.1, X4, 18.2

030 NEXT I

$032 M 1=M-1$

$034 F \cup R K=1 T$ TI

$036 D(K)=x(k+1)-x(k)$

$038 P(K)=U(K) / 6$

$0 \triangle 0 E(K)=(Y(K+1)-Y(K)) / D(K)$

042 NEXT K

$044 F(J K K=2 T H M 1$

$046 B(K)=E(K)-E(K-1)$

$0 \triangle 8$ NEXT K

$050 A(1.2)=-1.0-D(1) / U(2)$

$052 A(1,3)=D(1) / D(?)$

$054 A(2.3)=P(2)-P(1) * A(1,3)$

$056 A(2,2)=2 \cdot 0 *(F(1)+H(2))-\mu(1) * A(1,2)$

$058 A(2,3)=A(2,3) / A(2,2)$

$060 B(2)=B(2) / A(2,2)$

$062 \mathrm{FHK} K=3 \mathrm{TH} M 1$

$064 A(K, 2)=2 *(\mu(K-1)+\mu(K))-P(K-1) * A(K-1,3)$

$066 B(K)=B(K)-P(K-1) * A(K-1)$

$066 A(K, 3)=r(K) / A(K, 2)$

$070 B(K)=B(K) / A(K, 2)$

072 VEXI K

$074 U=U(M-2) / D(M-1)$

$076 A(M, 1)=1+0+A(M-2,3)$

$078 \quad A(M, 2)=-0-A(M, 1) * A(M-1,3)$

$080 R(M)=H(M-2)-A(M, 1) * B(M-1)$

$0 B 2 \zeta(M)=H(M) / A(M, H)$

$084: 12=$ in- 2

086 FNK $1=1$ TH $M 2$

$088 k=M-1$

$090 Z(K)=B(K)-A(K, 3) * Z(x+1)$

092 NEXT I

$094 Z(1)=-A(1,2) * Z(2)-A(1,3) * \angle(3)$ 


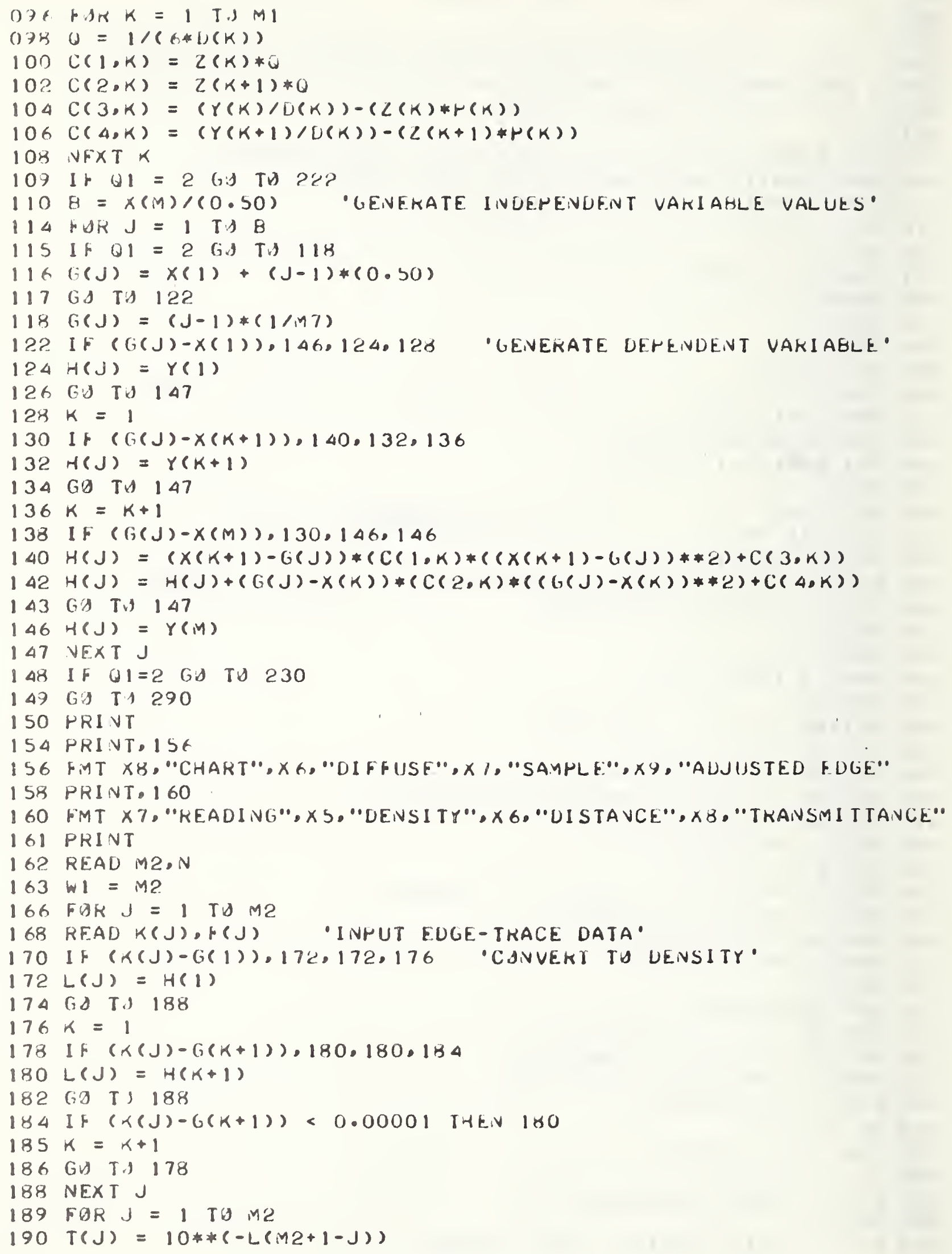




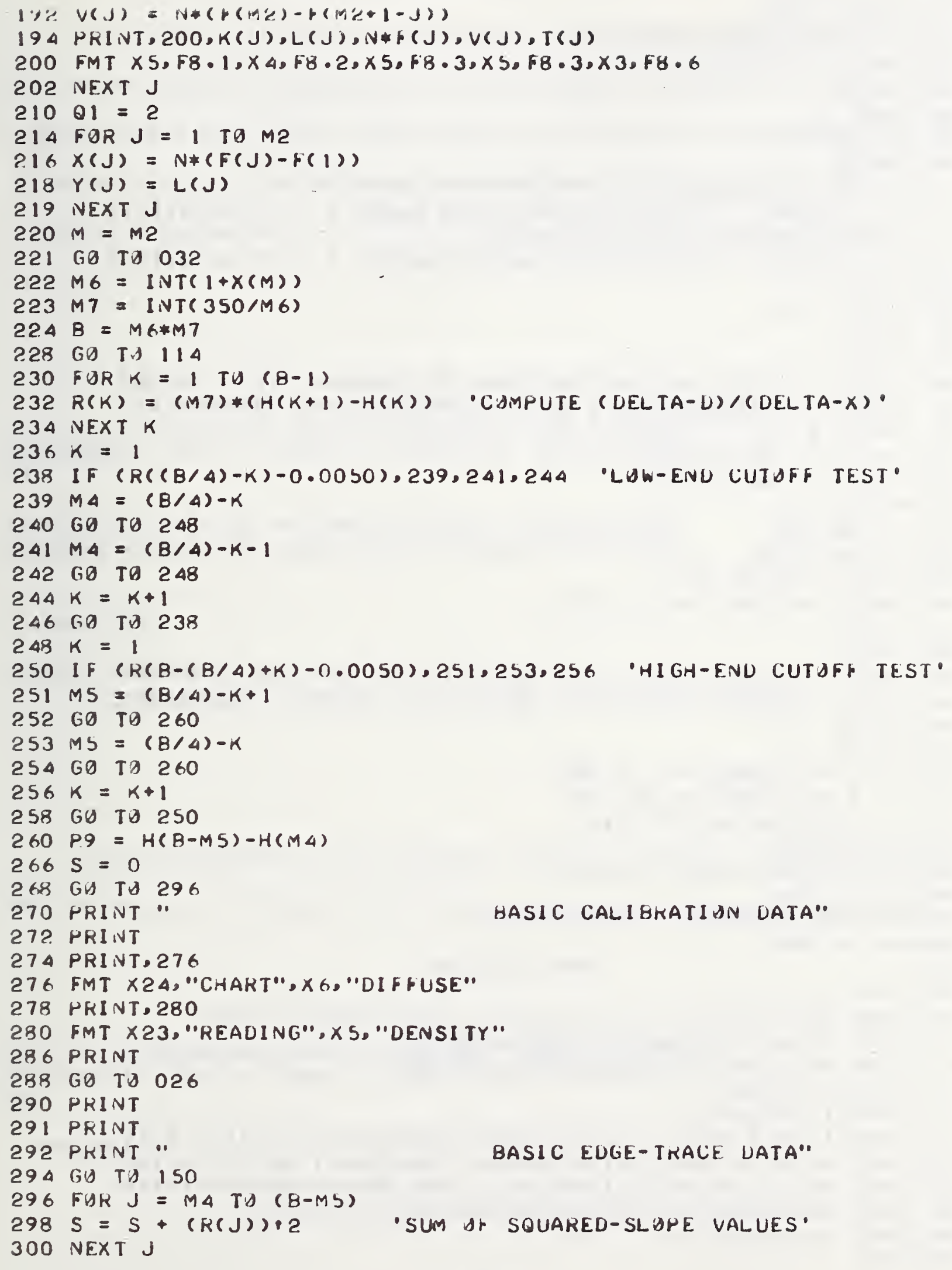


$301 G 2=(10 * 6) * S /(B-M S-M 4)$

$302 A=G 2 / P 9$

-calculate acutaince.

303 fin TH 310

304 HRINT, 305, A

305 FMT "ACUTANCE $=", 17$

306 FOR J $=1 \mathrm{~T} 15$

307 PRINT

308 NEXT J

309 GG TO 325

310 PRINT

312 PRINT, $314, H(B-M S), K(B-M S), R(B-M S+1)$

314 FMT "D-MAX $=", F B .2, \times 4, " 41 G H-E N U$ SLUPE $=", F 8.4, \times 8, P 8.4$

316 PRINT, $318, H(M 4), K(M 4), R(M 4-1)$

318 FMT "D-MIN $=", F K \cdot 2, \times 4, " L U W-E N D$ SLOPE $=", 18,4, \times 8, F 8 \cdot 4$ 320 HRINT

$322 \mathrm{GD} T \mathrm{TH} 370$

325 PRINT

326 PRINT

327 PRINT "IF MTH CALCULATIDNS AKE TO FOLLOW. TYRE I AHTEK !."

328 PRINT "OTHERWISE, TYPE 2, AND THE KUN WILL TERMINATE."

331 INPUT A

333 IF $A=1 \mathrm{GO}$ TA 338

334 IF $A=2$ GJ TH 999

336 PKINT

337 GA TO 325

338 FILES, DATAC

$339 F O R J=2 \mathrm{~T} O W \mathrm{~W}=1$

340 WRITE $2,(V(J)-V(2)), T(J)$

341 NEXT J

342 PRINT

343 HKINT "AN ELGE-DATA FILE HAS BLEIV SET UP WOW KUIV THE"

344 PRINT "PRWGRAM EMTPER TD DBTALIV THE TKAIVSRER FUIVCTIUN."

346 PKINT

347 GO TO 999

370 IF $A=100000$ Gr TH 382

371 IF $A \Rightarrow 10000$ GD TV 378

$374 A=I N T((A+3 \cdot 0) / 10) * 10$

376 GO TO 384

$378 A=I N T((A+50.0) / 100) * 100$

380 (iB) T.J 384

$382 A=I N T((A+500.0) / 1000) * 1000$

$3 \times 4$ Gis ID 304

$899 *$

900 DATA 11

910 UATA $0,0,1 \cdot 0,0.04,10 \cdot 5,0.345,17 \cdot 0,0 \cdot 60,25 \cdot 3,0.86$

912 DATA $41.0,1 \cdot 42,54 \cdot 5,1 \cdot 47,65 \cdot 0,2 \cdot 26$

914 DATA $72 \cdot 5 \cdot 2 \cdot 55,79 \cdot 0,2 \cdot 78,91 \cdot 3 \cdot 3 \cdot 20$

916 DATA 21.3 .048

917 DATA $15 \cdot 0.0 .20$

918 DATA $15.0,0.30,15 \cdot 3,0.65,16 \cdot 0,0.60,17.0,0.95,19.0,1.10$

920 DATA $20 \cdot 5 \cdot 1 \cdot 20,22.5,1 \cdot 30.25 \cdot 0 \cdot 1 \cdot 40,28 \cdot 0,1 \cdot 50.31 \cdot 5 \cdot 1.60$

922 DATA $35 \cdot 5,1 \cdot 70,40 \cdot 0,1 \cdot 60,45 \cdot 5 \cdot 1 \cdot 90,50 \cdot 5,2 \cdot 00,53 \cdot 0,2 \cdot 10$

924 DATA $5 t \cdot 5 \cdot 2 \cdot 25,57 \cdot 0,2 \cdot 30,58 \cdot 0,2 \cdot 45,58 \cdot 5 \cdot 2 \cdot 70$

925 DATA $58 \cdot 3,2 \cdot 80$

999 END 
At the end of the Acutance calculation, the program spaces enough lines to provide paper for trimming to an 11 -inch length and then asks the user to choose between two options. One of these is to proceed to the calculation of Transfer Function. The following is a printout of this, together with the affirmative response:

IF MTF CALCULATIONS ARE TU FULLOW. TYPE I AFTER $1 \cdot$ OTHERWISE, TYPE 2, AND THE KUN WILL TEKMINATE. 11

AN EDGE-DATA FILE HAS BEEN SET UH, NAW KUN THE PROGRAM EMTFER TU OBTAIN THE TRANSFER FUNCTIDIN.

\section{EXIT}

PBASIC EMTFER

The second option is the termination of the run without further calculation. The following is a printout of the alternate response to the program options.

IF MTF CALCULATIONS ARE TO FOLLOW, TYPE I AFTER 1. O THERWISE, TYPE 2, AND THE RUN WILL TEPMINATE. 12

999 EXIT 
ACUMTP has been designed to be used at NBS for calibration of high-quality edges. The rounding algorith therefore does not extend to values of acutance less than 1000 (11nes 370 through 384). For lower quality edges, this program should not be used. As a means of assessing this, examination of the listing of sample distance in the ADJUSTED EDGE TRANSMITTANCE column of F1gure 2 will provide a useful criterion. If the final distance value 18 less than 15 , the edge may be considered of sufflclently high quality to warrant further use of the program. A value larger than this will require program modifications which w11 not be discussed here. 
APPENDIX. B

EMTFER - A Program for Calculation of Transfer Function 
001 * MICHAKD E. SWING.232.08,X2159, HKWGKAM8 E.MTHEK

$002 *$

003 * THIS HRUGKAM CALCULATES TKANSFEK PUNCTIUN FKDM AN EDGEOOA * TKACE, THE DATA FOR WHICH IS DEKIVED FROM THE RKOGKAM

005 * CALLED ACUMTF. EMTFEK CANNDT BE EXECUTED WITHOUT FIKST

006 * RUNIVING ACUMTF. EMTFER ALSO SUPPLIES THE NECESSAKY

007 * DATA TO THE PRUGRAM MTFPLT FOK THE HLOTTING DF MTF.

$008 *$

$011 D I M F(200), L(200)$

012 DIM $X(40), Y(40), D(40), P(40), E(40), C(4,40), A(40,4)$

$013 D I M B(40), Z(\Delta 0), G(200), H(200)$

015 \%

016 PRINT

$01701=1$

$018 \mathrm{GQ} T 308$

$019 \mathrm{GD} T \mathrm{TV} 266$

020 FILES, DATAC, UATAB

$021 K=0$

022 READ $2, X(K+1), Y(K+1)$

023 IF END 2 THEN 030

026 PKINT,027, $X(K+1), Y(K+1)$

027 FMT $\times 15, F 8 \cdot 3, \times 11,58,6$

$028 K=K+1$

$029 \mathrm{GO} T \mathrm{TU} 022$

$030 M=K$

$03 !$ PRINT

$032 M 1=M-1$

034 FDR $K=1 \mathrm{TO} M !$

-calculate h I t-Cuefricients.

$036 D(K)=x(K+1)-x(K)$

$038 P(K)=D(K) / 6$

$040 E(K)=(Y(K+1)-Y(K)) / D(K)$

$O \triangle 2$ NEXT K

$O \triangle \triangle F O R K=2 T O M I$

$0 \Delta 6 B(K)=E(K)-E(K-1)$

$0 \triangle 8$ NEXT K

$050 A(1.2)=-1.0-D(1) / D(2)$

$052 A(1,3)=D(1) / D(2)$

$054 A(2,3)=P(2)-P(1) * A(1,3)$

$056 A(2,2)=2.0 *(P(1)+r(2))-r(1) * A(1,2)$

$058 A(2,3)=A(2,3) / A(2,2)$

$060 B(2)=B(2) / A(2,2)$

$062 \mathrm{FHKK} K=3 \mathrm{TH} M I$

$064 A(K, 2)=2 *(p(K-1)+P(K))-P(K-1) * A(K-1.3)$

$066 B(K)=B(K)-P(K-1) * B(K-1)$

$068 A(K, 3)=P(K) / A(K, 2)$

$070 B(K)=B(K) / A(K, 2)$

072 NEXT K

$0740=D(M-2) / D(M-1)$

$076 A(M, 1)=1+0+A(M-2,3)$

$078 A(M, 2)=-\theta-A(M, 1) * A(M-1,3)$

$080 B(M)=B(M-2)-A(M, 1) * B(M-1)$

$082 Z(M)=B(M) / A(M, ?)$

$084 M 2=M-2$ 
$086 \mathrm{FOR} I=1 \mathrm{TOM}$

$088 K=M-I$

$090 Z(K)=A(K)-A(K, 3) * Z(K+1)$

092 NEXT 1

$094 Z(1)=-A(1,2) * Z(2)-A(1,3) * Z(3)$

$096 \mathrm{FOR} K=1 \mathrm{TO} M \mathrm{Ml}$

$098 \theta=1 /(6 * D(K))$

$100 \mathrm{C}(1, K)=Z(K) * \theta$

$102 C(2, K)=2(K+1) * \theta$

$104 C(3, K)=(Y(K) / D(K))-(Z(K) * P(K))$

$106 C(4, K)=(Y(K+1) / D(K))-(Z(K+1) * P(K))$

108 NEXT $K$

$110 B=200$

112 FOR $J=1$ TO 8

-calculate edge-derivative.

$114 G(J)=(J-1) *(X(M)-X(1)) / B$

116 If $(G(J)-X(1)), 118,118,122$

$118 \mathrm{H}(\mathrm{J})=0$

$120 \mathrm{GO}$ TB 136

$122 K=1$

124 IF $(G(J)-x(K+1)), 126,126,132$

$126 H(J)=-3 * C(1, K) *(X(K+1)-G(J)) * 2 * 3 * C(2, K) *(G(J)-x(K)) * * 2$

$128 H(J)=H(J)-C(3, K)+C(4, K)$

$130 \mathrm{GO}$ TO 136

$132 K=K+1$

134 IF $(G(J)-X(M)), 124,118,118$

136 NEXT $J$

$140 \mathrm{FOR} J=1,199.2$ 'SET UP ARKAY FOR WEUDLE-INTEGRATIUN'

$142 H(J)=H(J) * 1$

144 NEXT J

$146 \mathrm{FBR} J=7,193,6$

$148 H(J)=H(J) * 2$

150 NEXT J

$152 \mathrm{FOR} J=2,194,6$

$154 H(J)=H(J) * 5$

156 NEXT J

$158 \mathrm{FBR} J=6.198 .6$

$160 H(J)=H(J) * 5$

162 NEXT J

$164 \mathrm{FOR} J=4.196 .6$

$166 H(J)=H(J) * 6$

168 NEXT J

$170 \mathrm{~S}=0$

$171 D=(0.30) *(X(M)-X(1)) / 8$

172 FOR $J=1$ TO 199

$174 S=S+H(J) * D$ 'AREA UNDER SPREAD FUNCTIUN'

176 NEXT J

$177 \mathrm{FGR} \mathrm{J}=1 \mathrm{~T} \theta 15$

178 PRINT

179 NEXT J

$180 \mathrm{GD}$ TO 290

$182 K=0$

$184 \mathrm{FOR} J=1 \mathrm{TO} 199$

$185 F=10$

$186 F(J)=\operatorname{CoS}((6.28318) * K * F *(0.001) * G(J))$

$188 \mathrm{~L}(J)=\operatorname{SIN}((6.28318) * K * F *(0.001) * G(J))$ 


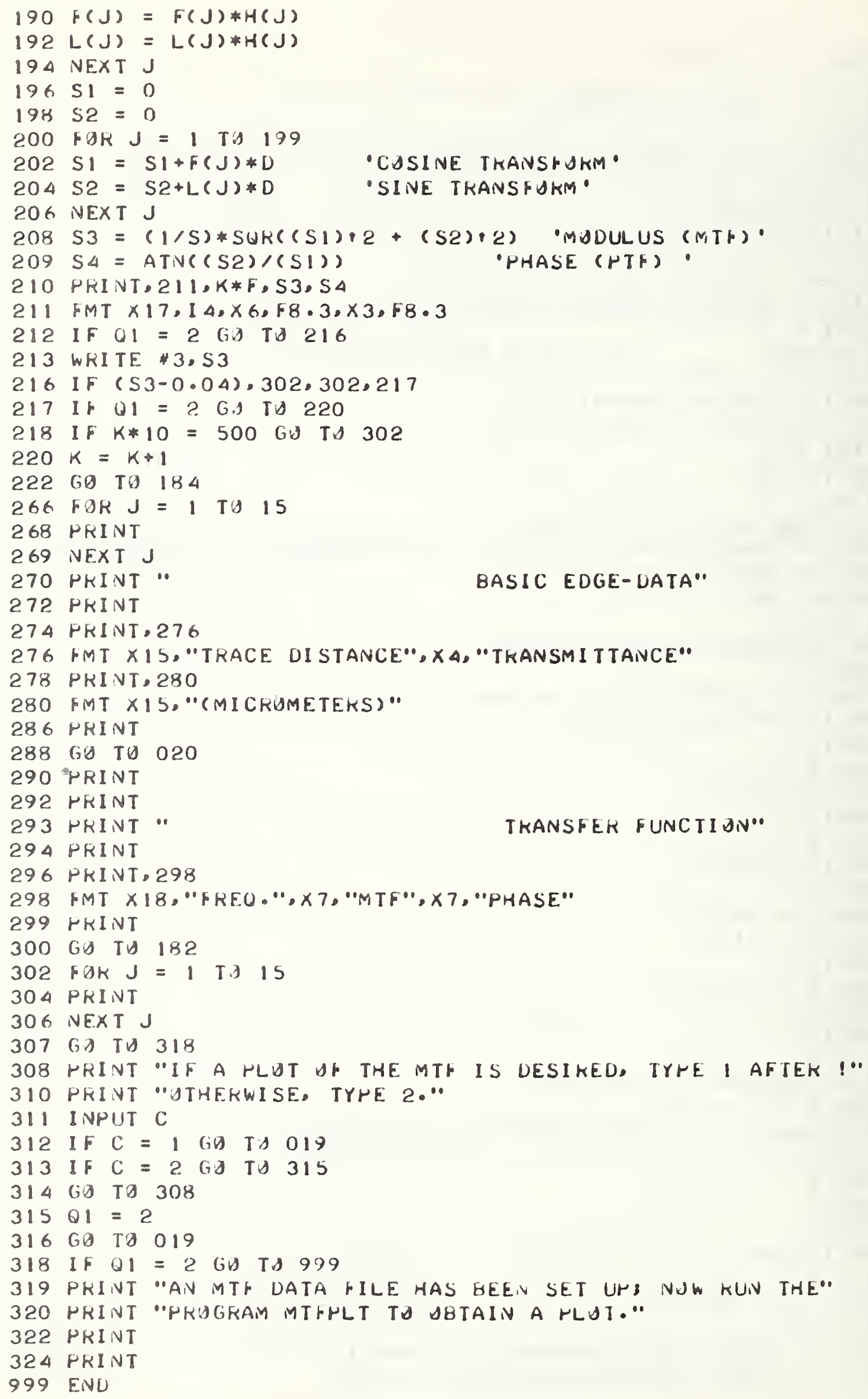


Prior to the transfer function calculation, the program asks the user to decide about a plot of the MTF:

IF A PLOT OF THE MTF IS DESIKEU. TYHE I AFIEK!

$\triangle T H E R W I S E$, TYPE 2 .

Should the user respond with a "2", the calculation will be terminated after the printing of the transfer function. When the response is a "l", a data flle is, prepared during calculation for use with the subsequent plotting program. The user is notified when the file is ready by the following statement:

AN MTF DATA FILE HAS BEEN SET UP, NOW KUIN THE PROGRAM MTFPLT TO OBTAIN A PLOT.

\section{EXIT}

The user now executes the program MTFPLT to obtain the plot.

When EMTFER obtains the edge information from the file set up by ACUMTF, it prints-ou a list. This can then be checked with the listing in the print-out of ACUMTF. It is not always necessary to list this information and there is a patch-routine to suppress the printing. It is as follows:

?PATCH EMTFER

BEGIN

026

027

266 PRINT

268

269

270

272

274

276

278

280

286

?BASIC EMTFER 
APPENDIX C

MTFPLT - A Program for Plotting Transfer Function 
001 RICHARD E. SWING, 232.08, X2159, PKOGRAM\& MTFPLT 002 *

DO3 * THIS PRGGRAM PLOTS THE MODLLATIUN TRANSFER FUNCTION

OOA * PKODUCED BY THE PROGRAM CALLED EMTFER. IT IS THE THIRD

005 * IN THE SEQUENCE...ACUMTF-EMTFER-MTFPLT.... AND CANNOT

006 * BE EXECUTED WITHOUT THE DATA PRODUCED BY THE OTHER TWO

007 * PROGRAMS.

$008 *$

016 DIM V(30),A(30), M( 50$)$

018 PRINT

020 FILES, DATAB

$030 K=0$

040 READ 3.M(K)

050 IF END 3 THEN 080

$060 k=k+1$

070 GB TB 040

$080 M=K-1$

082 PRINT

087 PRINT

090 FOR J $=0$ TO 25

$100 \mathrm{~V}(\mathrm{~J})=0$

$110 A(J)=0$

120 NEXT $J$

$130 F O R \mathrm{~J}=0 \mathrm{TO} \mathrm{M}$

$140 \mathrm{~K}=0$

150 If $((25-K) * 0.04-M(J)), 160,160,190$

$160 V(K)=1$

$170 A(K)=A(K)+1$

180 G8 TO 250

190 If $((25-K) \star 0.04-M(J))<0.0400$ GO TO 220

$200 K=K+1$

$210 \mathrm{GO}$ TO 150

220 IF $((25-K) * 0.04-M(J)) \ll 0.0200$ G6 TO 160

$230 V(K+1)=1$

$235 A(K+1)=A(K+1)+1$

250 NEXT $J$

275 FOR J $=1$ TO 15

280 PRINT

285 NEXT J

290 PRINT. 295

295 FMT X24, "MODULATION TRANSFER FUNCTION"

300 PRINT

305 PRINT

310 PRINT

311 FOR J $J 1$ TO 2

312 PRINT

313 PRINT $\cdots$

314 NEXT J

315 FOR J $=0$ TO 24

320 PRINT" "3

325 IF $\mathrm{J}=0 \mathrm{GD}$ TO 360

330 IF $((25-J) * 4 / 5)=I N T((25-J) * 4 / 5)$ THEN 350

335 PRINT

340 PRINT "\$+"

345 GO TO 390

350 PRINT $(25-J) *(0.04) 3$

355 GO TO 380 


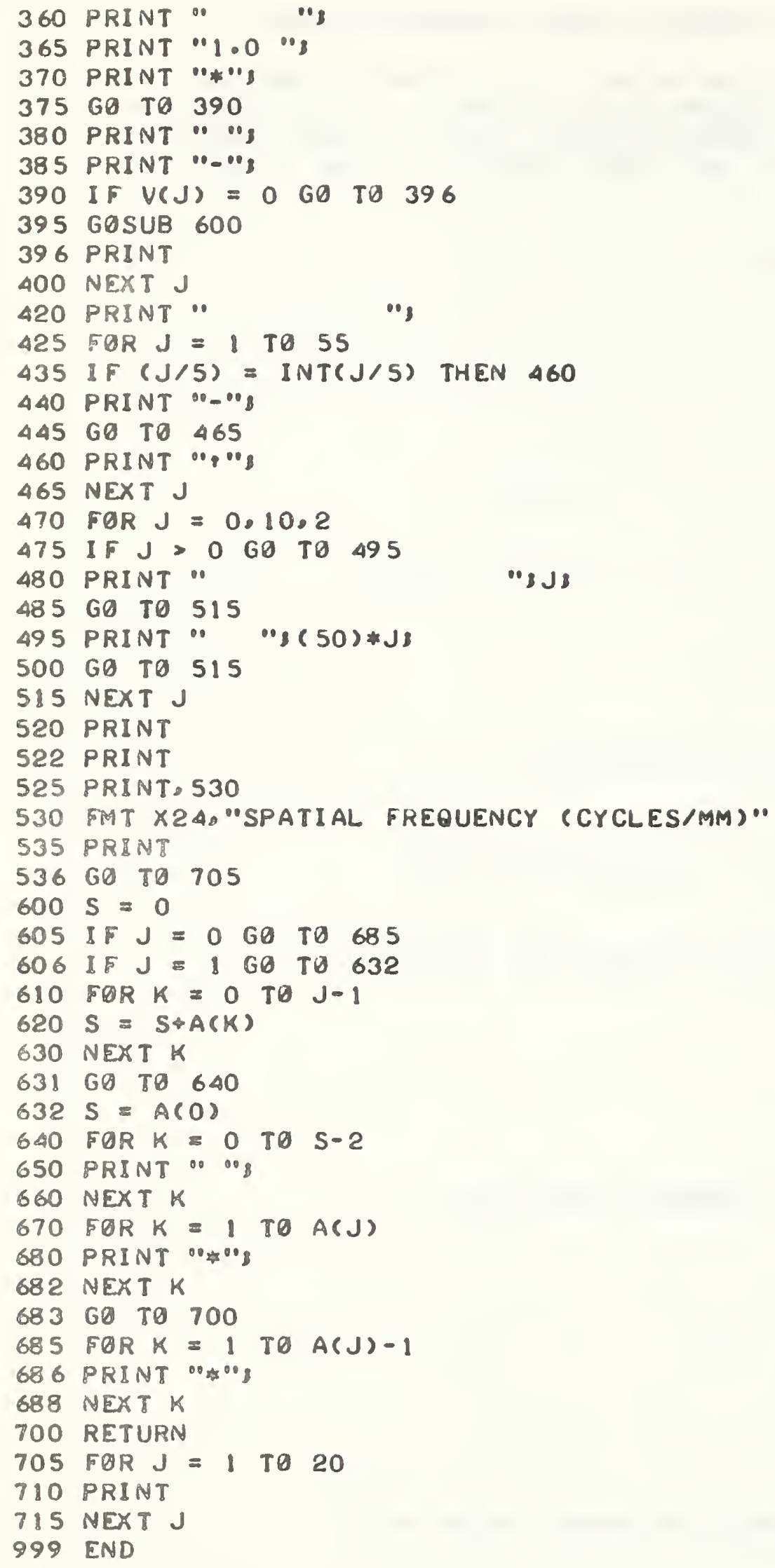


NBS.114A (REV. 7.73)

\begin{tabular}{|c|c|c|c|}
\hline $\begin{array}{l}\text { U.S. DEPT. OF COMM. } \\
\text { BIBLIOGRAPHIC DATA } \\
\text { SHEET } \\
\end{array}$ & $\begin{array}{l}\text { 1. PEBIII ATION OR RFPORT NO. } \\
\text { NBSTR } 75-699\end{array}$ & $\begin{array}{l}\text { 2. Gov't Accession } \\
\text { No. }\end{array}$ & 3. Recipient's Accession No. \\
\hline \multicolumn{3}{|l|}{ 4. TITLE AND SUBTITLE } & 5. Publication Date \\
\hline \multicolumn{3}{|c|}{ THE CALIBRATION OF PHOTOGRAPHIC EDGES AT NBS } & 6. Performing Organization Code \\
\hline \multicolumn{3}{|c|}{ Richard E. Swing } & 8. Performing Organ. Report No. \\
\hline \multicolumn{3}{|c|}{ 9. PERFORMING ORGANIZATION NAME AND ADDRESS } & 10. Project/Task/Work Unit No. \\
\hline \multicolumn{3}{|c|}{$\begin{array}{l}\text { NATIONAL BUREAU OF STANDARDS } \\
\text { DEPARTMENT OF COMMERCE } \\
\text { WASHINGTON, D.C. } 20234\end{array}$} & \begin{tabular}{|l}
2320187 \\
11. Contract/Grant No.
\end{tabular} \\
\hline \multirow{2}{*}{\multicolumn{3}{|c|}{ 12. Sponsoring Organization Name and (omplete Address (Street, City, State, ZIP) }} & $\begin{array}{l}\text { 13. Type of Report \& Period } \\
\text { Covered } \\
\text { Interim Report }\end{array}$ \\
\hline & & & 14. Sponsoring Agency Code \\
\hline
\end{tabular}

15. SUPPI.EMENTARY NOTES

16. ABSTRACT (A 200word or les a tactual summary of moat sienilicant information. Il documant includes a significant bibliography or literature survey, mention it here.)

The method by which photographic edges made at NBS are calibrated is presented and discussed in some detail. The programs assoclated with the computational aspects of the analysis are listed, covered in namative form, and their limitations and options are presented. The possible use of these edges to determine microdensitometer transfer function is discussed and limitations and relative error of all the calculations and procedures are covered in detail. Program listings are in BASIC language.

17. KEY WORDS (six to twelve entries; alphabetical order; capilalize only the firat letlof of the first key word unless a proper name; separated by semicolons)

Acutance; Calibration; Computer Programs; Microdensitometry; Photographic Edges; Transfer Function.

18. AVAILABII.ITY Enlimited

For Official Distribution. Do Not Release to NTIS

[ Order From Sup. of Doc., U.S. Government Printing Offuce Washington, D.C. 20102, SD Cat. No. C13

[X] Order From National Technical Information Service (NTIS) Springfield, Virginia 22151

\begin{tabular}{|l|c|}
\hline $\begin{array}{l}\text { 19. SFCURITY CLASS } \\
\text { (THIS REPURT) }\end{array}$ & 21. NO. OF PAGES \\
UNCL ASSIFIED & 38 \\
\hline $\begin{array}{l}\text { 20. SECURITY (.LASS } \\
\text { (TIIS PAGE) }\end{array}$ & 22. PriCe \\
UNCLASSIFIED & $\$ 3.75$ \\
\hline
\end{tabular}






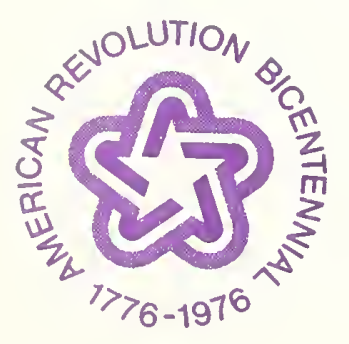

